\title{
HELLER'S MYOTOMY: A HUNDRED YEARS OF SUCCESS!
}

\author{
Cardiomiotomia a Heller: 100 anos de sucesso!
}

\author{
Nelson Adami ANDREOLLO ${ }^{1}$, Luiz Roberto LOPES $^{1}$, Osvaldo MALAFAIA ${ }^{2}$ \\ ${ }^{1}$ Faculdade de Ciências Médicas da Universidade Estadual de Campinas, UNICAMP, Campinas - SÃo Paulo - Brazil \\ Universidade Federal do Paraná - UFPR/Faculdade Evangélica do Paraná- FEPAR - Brazil
}

$\mathrm{O}$ n April 14, 1913, Monday, the young surgeon of 36 years, Ernst Heller, assistant professor of Erwin Payr, Director of the Surgical Clinic of the University of Leipzig in Germany, while operating a patient with idiopathic achalasia of the esophagus, performed for the first time a cardiomyotomy extramucosal, leaving his enormous contribution to the history of esophageal surgery, in the 20th century ${ }^{1}$.

Ernst Heller was born in 1877 and as a young surgeon had in its formation the influence of various known surgeons of the time, such as Gottstein and Heyrovsky. Between 1914 and 1918 he served as a surgeon in the first World War, in the front. He returned to Leipzig in 1918 as chief surgeon of Saint George County Hospital. In 1949 he became Professor at the University of Leipzig and died at the age of 87 on November 2, 1964, and published over 80 scientific papers during their academic life ${ }^{2}$.

The record of his first extramucosal cardiomyotomy was published in the journal Mitt Grenzgeb Med Chir, describing in detail the clinical case, the surgical technique employed including figures, the evolution of the patient and reviews about the disease ${ }^{1,2}$.

This is a briefing of original Heller's report:

"In the first section of the Archiv für Chirurgie klinische 1913, described a Heyrovsky subdiafragmatic esofagogastric anastomosis that performed successfully in two cases of socalled "idiopathic dilatation of the esophagus". Shortly after the publication of this notice, came to the care of the surgical clinic of Leipzig, a patient with chronic saculiform cardiospasm and marked dilation of the esophagus, which seemed appropriate the surgical treatment for elimination of suffering. Under the impression of Heyroyvsky successes, I intend to perform the surgery in the same way. During the surgery, however, due to certain difficulties and after theoretical considerations, I ended up running a different intervention from the original plan, performing a cardioplasty extramucosal. In advance as I want to note that the functional point of view was very exceptionally satisfactory, and this change in the surgical procedure has, in my view, important practical advantage compared to the operational measures proposed and followed in the treatment of cardiospasm by esophageal dilatation, I wish allowing me to share briefly the case....

Clinical history: The patient of 49 years old has suffered
30 years of dysphagia. About the beginning of suffering and possible precipitating factors, hereditary nervous load, and also on the degree of discomfort at the beginning of a suffering or fluctuations in the severity of the nuisance was not able to accurately inform nothing more....

At the time and for years he only exceptionally could swallow solid food. Depended essentially liquefied food and doughy, requiring long time to regularly intake, and always sought to push the food down by copious fluid. Also certain movements, particularly forceful extension of the trunk, facilitated the passage of food from the stomach. It remained so for years in a regular nutritional status but yet sufficiently preserved .... esophagus ....

Diagnosis: chronic cardiospasm fusiform dilatation of the

Operation (14 April 1913): Opening the left costal arch as Marwedel, resulted in very good access to the region of the cardia. The accessibility to the cardia was facilitated by addition of a gastroptosis degree. Along the greater curvature bind some branches of art. gastr. brevis near the lesser curvature, some terminal branches of art. gastr. sinister. A strip of gauze is wrapped around the cardia left free, and her stomach is pulled down ....

Firstly, by a longitudinal section of $8 \mathrm{~cm}$ long, held on the front surface of the esophagus in the region of $2 \mathrm{~cm}$ initiated dilatation and for a short section on the cardia to the fundic portion of the stomach, a slit is formed in the longitudinal muscle the esophagus. This opens up a bit and let the discerning well demarcated annular layer of muscles. Then carefully sectioned in equal extent also the annular muscle. Its thickness arrives at the contracted, an estimated about 1-2 mm, and the thickness region above the spindle on $4 \mathrm{~mm}$. Immediately after the last section of the annular fibers of the muscles, the edges of the incision open and let you see clearly the design of the submucosal venous unchanged. After conducting longitudinal incision previous dilatation of the lower esophagus has not proved considerable. Thus, we carried out a longitudinal incision similar also on the posterior surface of the esophagus facing. After this second longitudinal incision, the muscle wall of the esophagus at the previously contracted, retreated to the right and left strips $1 \mathrm{~cm}$ wide, and in its midst, the loose layer of mucosa, free at its greatest extent, which enlarges the lumen was now immediately over almost two fingers thick ....

Evolution: The recovery was disrupted by pneumonia in both lower lobes, which, however, was completely overcome. From the day after the operation, the patient received any form of food, including solid food: bread, meat, potatoes. From the beginning, he could swallow any kind of food without difficulty 
Since the large and double sphincter section fulfills this purpose have the expectation of success in the above case. By surgical method here exposed, by preventing the opening of the light of the mucosa in the esophagus and a suture, surgical risk is considerably reduced. So, I guess you could recommend cardioplasty extramucosal, for cases of chronic dilatation with cardiospasms of the esophagus:

1) in which conservative treatment was applied unsuccessfully

2) there is compromised nutritional status of patients,

3) inexistance any other contraindications to surgery for most rides." 1,2

The last review of the patient operated by Heller in 1921 - about eight years after surgery -, said that he was in good health and well nourished, with 57 years old, eating any kind of food, chewing them slowly. And on this occasion the radiological examination of the esophagus showed some degree of narrowing of the cardia. After this date, Heller said he lost contact with the patient ${ }^{2}$.

Although the surgery described by Heller in 1914 became the preferred surgical procedure to treat achalasia worldwide, it was initially not widely accepted on his own country. According to the literature, Heller continued employing anterior and posterior myotomies; however, the Dutch surgeon De Bruine Groeneveldt limited the procedure just to an anterior myotomy. Later, is credited to Zaaijer the procedure be done only with an anterior myotomy, propagating the operation throughout Europe. In England and North America, Heller operation came into use about 50 years later and with restrictions, since it facilitated the occurrence of gastroesophageal reflux $x^{2,3}$.

Knowing that the proposed cardiomyotomy by Heller would cause gastroesophageal reflux, several anti-reflux procedure were associated by many surgeons worldwide ${ }^{3}$.

In Brazil, the Heller's operation began to be used to treat our megaesophagus associated with Chagas disease since 1922, having been firstly performed by Walter Seng ${ }^{4}$. However, it was Professor Henrique Walter Pinotti at the University of São Paulo who described in 1974 a specific technique of antireflux fundoplication, with three layers, and associated it to the Heller's myotomy, popularizing this procedure throughout the country ${ }^{5,6}$. It is recommended in the surgical treatment of non-advanced megaesophagus. More recently, with advances in laparoscopic surgery, is now also performed by laparoscopy minimizing hospital stay, the postoperative pain and allowing early return of the patient to work activity ${ }^{7,8}$. And currently, considering its widespread use throughout the country, both in the treatment of chagasic megaesophagus or idiopathic achalasia, the procedure has become accepted and called Heller-Pinotti?.

Finally, it is undoubtedly that the contribution that Ernst Heller gave to the esophageal surgery in the $20^{\text {th }}$ century was enormous. And in these one hundred years, the concept of Heller's myotomy was extended to the treatment of other esophageal motor disorders with good results, such as nutcracker esophagus, hypertensive lower esophageal sphincter, diffuse spasm, and others, since that such diseases cause lower sphincter achalasia?.

The Heller's myotomy, associated with anti-reflux procedure indicated in non-advanced megaesophagus of Chagas disease or idiopathic achalasia of the esophagus, provides significant relief of dysphagia and regurgitation after meals, improves nutrition, weight gain and, therefore, gives better quality of life.

\section{REFERENCES}

1. Heller E. Extramukose Cardiaplastik beim chronischen Cardiospasmus mit Dilatation des Oesophagus. Mitt GrenzgebMed Chir. 1914;27141-9.

2. Payne WP. Heller's contribution to the surgical treatment of achalasia of the esophagus. Ann Thorac Surg. 1989;48:876-881

3. Andreollo NA, Earlam RJ. Heller's myotomy for achalasia: is an added anti-reflux procedure necessary? Br J Surg. 1987;74:765-9.

4. Seng W. Cirurgia do esophago. Bol Soc Med Cir São Paulo. 5:128133, 1922.

5. Pinotti HW, Gama-Rodrigues JJ, Ellenbogen G, Arab-Fadul R, Raia A. New basis for the surgical treatment of megaesophagus: esophagocardiomyotomy with esophagus-fundus-gastropexy. AMB Rev Assoc Med Bras. 1974;20(9):331-4.

6. Felix VN, Cecconello I, Zilberstein B, Moraes-Filho JP, Pinotti HW, Carvalho E. Achalasia: a prospective study comparing the results of dilatation and myotomy. Hepatogastroenterology. 1998;45(19):97-108.

7. Pinotti HW. First development of cardiomyotomy by videolaparoscopy: a new perspective in the achalasia treatment. ISDE News. 1991;10:8.

8. Lopes LR, Braga Nda S, Oliveira GC, Coelho Neto Jde S, Camargo MA, Andreollo NA. Results of the surgical treatment of nonadvanced megaesophagus using Heller-Pinotti's surgery: Laparotomy vs. Laparoscopy. Clinics (Sao Paulo). 2011;66(1):41-6.

9. Kataka N, Sakuramoto S, Yamashita K, Shibata T, Moriya H, Kikuchi S, Watanabe M. Recent Trends in the Management of Achalasia. Ann Thorac Cardiovasc Surg. 2012;18(5):420-8. 